\title{
Molecular Electrocatalysts for the Hydrogen Evolution Reaction: Input from Quantum Chemistry
}

\author{
Alexandre Barrozo ${ }^{+*}$ and Maylis Orio ${ }^{+*[a]}$
}

In the pursuit of carbon-free fuels, hydrogen can be considered as an apt energy carrier. The design of molecular electrocatalysts for hydrogen production is important for the development of renewable energy sources that are abundant, inexpensive, and environmentally benign. Over the last 20 years, a large number of electrocatalysts have been developed, and considerable efforts have been directed toward the design of earth-abundant, first-row transition-metal complexes capable of promoting electrocatalytic hydrogen evolution reaction (HER). In this context, numerical approaches have emerged as powerful tools to study the catalytic performances of these complexes. This review covers some of the most significant theoretical mechanistic studies of biomimetic and bioinspired homogeneous HER catalysts. The approaches employed to study the free energy landscapes are discussed and methods used to obtain accurate estimates of relevant observables required to study the HER are presented. Furthermore, the structural and electronic parameters that govern the reactivity, and are necessary to achieve efficient hydrogen production, are discussed in view of future research directions.

\section{Introduction}

Arguably, one of the biggest challenges we face in the 21st century is minimizing the impact of energy consumption and production, which are significant contributors to manmade climate change. ${ }^{[1]}$ Therefore, the development of renewable energy sources that are environmentally friendly, affordable, and effective is paramount. Hydrogen is regarded as a promising molecular fuel to address this problem. ${ }^{[2]}$ The utilization of such energy sources relies on catalysts to facilitate the process of the formation and cleavage of the chemical bond in $\mathrm{H}_{2}$. They often accelerate the reactions by utilizing proton-coupled electron transfer (PCET), which integrates the motions of electrons and protons to avoid high-energy intermediates.

To date, platinum performs best among catalysts able to produce $\mathrm{H}_{2}$, through water splitting. ${ }^{[3]}$ However, due to its scarcity and cost, there has been wide interest in finding alternatives made of non-noble transition metals. This quest has been inspired by hydrogenases, which are organometallic enzymes that employ nickel and/or iron centers in their active sites. Their catalytic performances rival that of commonly used platinum catalysts for hydrogen production. With turnover rates of up to $10^{4} \mathrm{~s}^{-1}$, thermostability, and low overpotentials, ${ }^{[4]}$ hydrogenases have been studied as templates for the synthesis of new organometallic catalysts. Unfortunately, due to their intricate architectures, there has not yet been precise agreement

[a] Dr. A. Barrozo, ${ }^{+}$Dr. M. Orio ${ }^{+}$

Aix Marseille Univ, CNRS

Centrale Marseille, iSm2, $\square$ postcode? $\square$ Marseille (France)

E-mail:maylis.orio@univ-amu.fr

Homepage: $h$ ttp://ism2.univ-amu.fr/fr/biosciences/biosciences

$\left.{ }^{+}\right]$These authors contributed equally to this work.

(iD) The ORCID identification number(s) for the author(s) of this article can be found under:

https://doi.org/10.1002/cssc.201901828.

on how they function. ${ }^{[5]}$ Moreover, from a theoretical point of view, the size and composition of their active sites make them challenging to study. ${ }^{[6]}$

Due to the aforementioned difficulties, a vast number of articles have been published on biomimetic ${ }^{[7]}$ or bioinspired ${ }^{[8]}$ systems; these consist of either simpler or adapted versions of the metal centers found in the active sites of hydrogenases (Figure 1). The idea is to facilitate the analysis of the hydrogen evolution reaction (HER) in the metal centers, looking for the essential elements that could be used to develop new catalysts with non-noble transition metals. ${ }^{[9]}$ Optimization of these com-
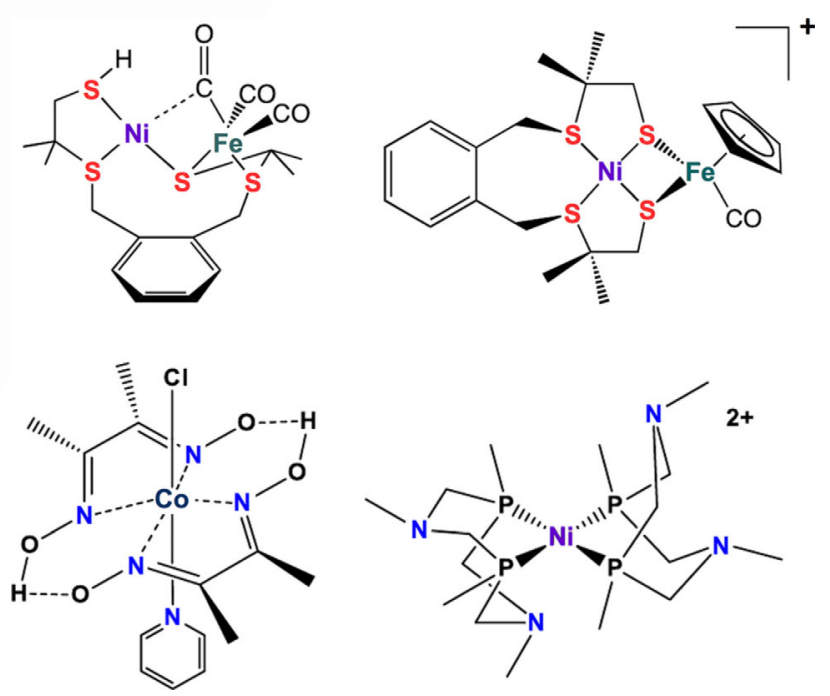

Figure 1. Selected biomimetic (top) and bioinspired (bottom) hydrogen evolution catalysts. ${ }^{[7,8]}$ The examples show how electrocatalysts can have completely different ligands and metal centers, and yet exhibit similar reactivity. In Section 3, we discuss some of these examples. 
plexes requires careful analysis of their catalytic cycles. The use of computational methods is indispensable in testing multiple hypotheses, for which a comparison with experimental observables aids in elucidating the steps of the catalytic pathway. Quantum chemical calculations allow for studying the geometry of the complexes, and how they can change upon chemical and electrochemical reactions with their surroundings. Analysis of the energetics of protonation taking place at different parts of a catalyst allow differences in $p K_{\mathrm{a}}$ values across the complex to be obtained. Careful study of the energy landscape for the various intermediates formed upon reduction and protonation tells us the most likely mechanisms that are taking place. They give us dynamic details of the process and explain how a general acid can react with the catalyst for the formation of $\mathrm{H}_{2}$.

All of this information can be compared to 1) crystallographic data, for structural information and validation of methodology in terms of geometry optimization, according to the choice of level of theory; 2) cyclic voltammograms, for measurements of redox potentials, and analysis of the electrochemical steps (electron transfer (ET)) in the catalytic cycle; 3) EPR spectra, for accessed spin states upon reduction, allowing for the correct assignment of the electronic states at every step; and 4) potential-pH (Pourbaix) diagrams, which depict the most thermodynamically stable species for given reduction potentials and $\mathrm{pH}$ values. This last item is particularly useful because it allows us

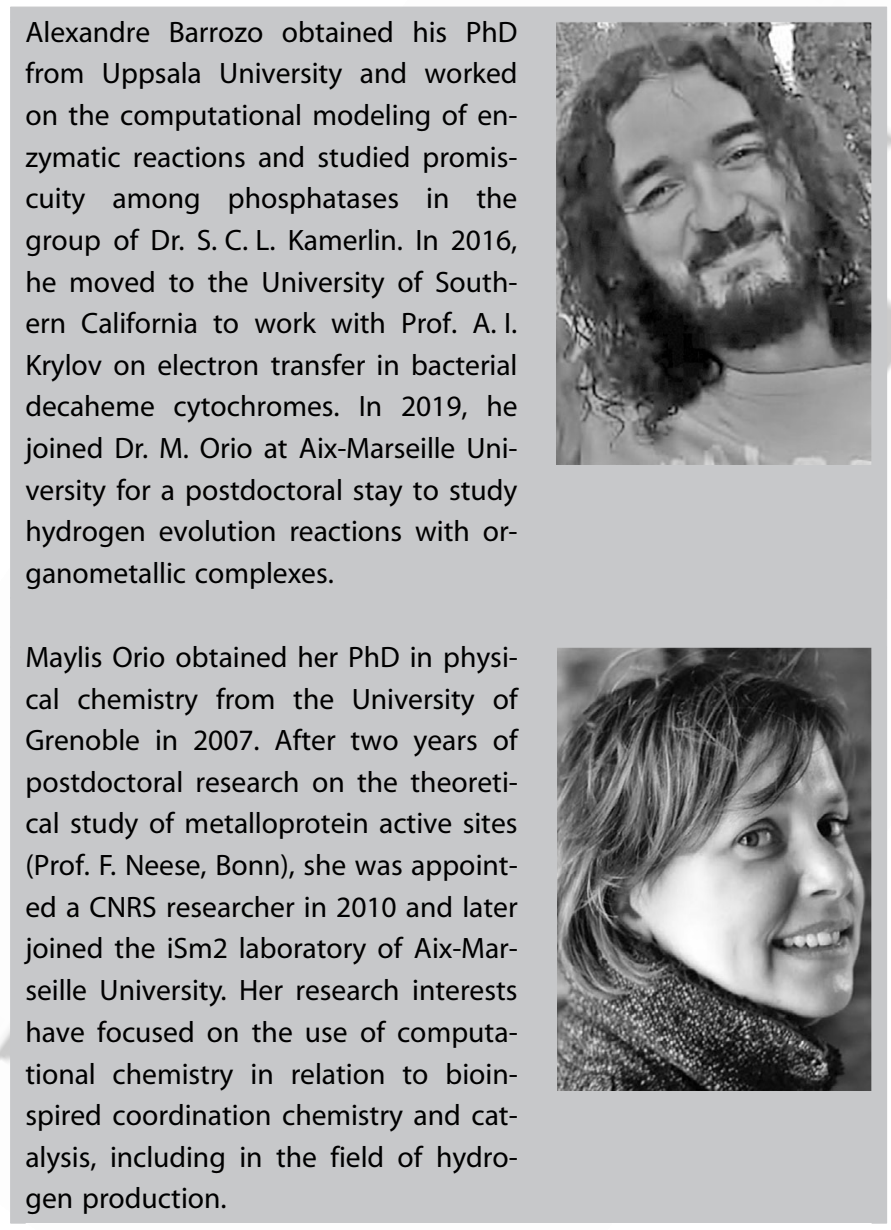

to evaluate the stability of all possible intermediate species over a broad range of $\mathrm{pH}$ values.

This review focuses on theoretical mechanistic studies of biomimetic and bioinspired homogeneous catalysts for the HER inspired by hydrogenases. We discuss the many possible steps that could compose a catalytic cycle, and how the use of quantum chemical methods can help us to choose which ones are the most likely to describe the reactivity taking place. We review recent research into various catalysts to show this process of mechanistic investigation. First, we discuss distinct types of catalytic cycles that could take place. Then, we follow with the current understanding of the catalytic cycle of recently developed and characterized bioinspired and biomimetic homogeneous catalysts for the HER. Hopefully, we can give the reader an idea about the current state-of-the-art approaches in deciphering the mechanisms involved in HER catalysis, and how this can lead to the development of new homogeneous catalysts

\section{Studying the HER}

$\mathrm{H}_{2}$ is one of the simplest molecules found in nature, and is composed of two protons and two electrons. Its formation can occur in various ways, ranging from each proton holding a single electron (two $\mathrm{H}$ atoms), to cases in which protons can bind to surfaces or molecular complexes with an excess of two electrons, leading to bond formation. Additionally, protons and electrons can have coupled behavior, in which proton movement can trigger an ET, and vice versa. This leads to dynamically more complex chemical reactions, known as PCET. They can vary in terms of the timescale and order of the transfer steps, sometimes involving the formation of transient intermediates, which can be challenging to characterize, experimentally and theoretically. Thus, studying the HER involves assessing multiple viable scenarios. We discuss some of the approaches employed to inspect free energy landscapes. These involve calculations of redox potentials over various conditions, identification of protonation sites (if any) through estimations of relative $\mathrm{pK}_{\mathrm{a}}$ values, and studying the stability of the many possible oxidation and protonated states through Pourbaix diagrams. In this section, we review some of the methods that have been used recently to obtain accurate estimates of relevant observables required to study the HER. These approaches are used in various works that are discussed later herein. More specific quantum dynamic information on the coupling between electrons and protons is omitted. The interested reader is referred to a more specialized review by Hammes-Schiffer, which discusses PCET in the same context as that presented herein. ${ }^{[10]}$

\subsection{Redox potential and $\mathrm{p} K_{\mathrm{a}}$ calculations with DFT}

Redox potentials are experimental observables related to the Gibbs free energy change $(\Delta G)$ of a redox process. They are defined as $E=-\Delta G / n F$, in which $n$ is the number of electrons transferred in the cell and $F$ is the Faraday constant. Calculating $E$ requires the evaluation of $\Delta G$ for the oxidation or reduction process in question in the environment where it takes 
place, that is, Red(s) $\rightarrow$ Ox(s), in which "s" stands for the solvent in which the catalyst is contained. Free energy calculations are challenging because accurate estimates rely on extensive sampling. It turns out that, for homogeneous HER catalysts, there are computationally inexpensive approaches. A common strategy is based on the Born-Haber thermodynamic cycle, which involves calculations of the process in the gas phase and solution (Scheme 1). The idea is that the cycle of any thermodynamic quantity sums to zero. The free energy change for the redox reaction in solution, $\Delta G_{s}$ is computed from the free energy change in the gas phase $\left(\Delta G_{g}\right)$ and solvation free energies of the reduced $\left(\Delta G_{\mathrm{s}, \text { red }}\right)$ and oxidized species $\left(\Delta G_{\mathrm{s}, \mathrm{ox}}\right)$ : $\Delta G_{\mathrm{s}}=\Delta G_{\mathrm{g}}+\Delta G_{\mathrm{s}, \mathrm{ox}}-\Delta G_{\mathrm{s}, \mathrm{red}}$.

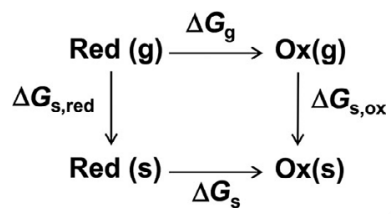

Scheme 1. Born-Haber cycle used for estimating the free energy change associated with the oxidation process of a molecule in solvent.

Oxidation or reduction in the gas phase, $\Delta G_{g}$ can be computed in various ways. A classical approach involves free energy perturbation calculations, in which a set of molecular dynamics simulations are performed with force field parameters that change linearly between reduced and oxidized states. ${ }^{[11]}$ This approach requires a reliable parameterization for the complex of interest in different oxidation states; this task can be time-consuming. A simpler approach involves ab initio methods and DFT calculations. In particular, DFT has been used extensively due to its affordability in handling large organometallic complexes. ${ }^{[7-9]}$

If using DFT, free energies are computed as a sum of electronic energy, zero-point energy, and thermal corrections. These properties can be obtained through frequency calculations, as implemented in various quantum chemistry packages, such as Gamess ${ }^{[12]}$ and ORCA. ${ }^{[13]}$ For $\Delta G_{g}$, the structures of the complex in its oxidized and reduced forms are initially optimized in vacuum and a frequency calculation is then performed. A similar approach is applied to obtain $\Delta G_{\text {s,red/ox, }}$ but it now needs to account for the solvent. A simple and inexpensive method to emulate the solvent effect involves the use of an implicit solvent model, such as COSMO and $\mathrm{SMx}{ }^{[14]}$ which can also be found in the software packages mentioned above. We simply take the structures of the reduced and oxidized complex in vacuum and add the implicit solvent in the frequency calculation. Although this can be a fast approach, care must be taken as conformational changes can take place in the complex upon solvation; thus yielding inaccurate results. Sometimes it is possible to cut corners and obtain a direct $\Delta G_{\text {s }}$ involving solely the reduced and oxidized states in solvent, if geometry optimization of the complex in the solvent is computationally affordable. ${ }^{[15]}$

All discussions above apply to the estimation of $\mathrm{p} K_{\mathrm{a}}$ values. Particularly, sampling in this case is even more important be- cause the protonation of a chemical group can lead to the formation of new hydrogen bonds, with the solvent, ions in solution, or the complex itself. ${ }^{[16]}$ The thermodynamic cycle from Scheme 1 is essentially the same, with reduced and oxidized states substituted by protonated and unprotonated states. In principle, absolute estimates can be achieved. These require proton solvation free energies. Nevertheless, even with an accurate estimate of such observables, DFT can still be off by several units of $\mathrm{pK}_{\mathrm{a}} \cdot{ }^{\left[{ }^{[7]}\right.}$ Nevertheless, the errors in DFT could be cancelled upon comparing different protonation sites. Rather than looking at absolute values, we can measure relative $\mathrm{p} K_{\mathrm{a}}$ values. They can be used together with some estimate of the absolute value to enable us to obtain quantitative free energy landscapes. These references can come, for instance, from cyclic voltammograms for solutions titrated with different acids with known $p K_{\mathrm{a}}$ values, in which there is a change in the wave as the complex becomes catalytic. ${ }^{[17]}$ Additionally, mechanistic conclusions can also be drawn from relative values alone. ${ }^{[18]}$

\subsection{Pitfalls with DFT}

We have at our disposal a gamut of exchange-correlation functionals, each of which is tailored to reproduce key properties in a specific class of molecules. Thus, care must be taken in the appropriate choice of functional because different sets of molecules can have completely different behavior regarding correlation energies. ${ }^{[19]}$ Ideally, upon approaching a new system, one needs to either seek previous studies in similar compounds as a means to validate the choice of a given level of theory, or perform benchmark studies with different setups. These involve a comparison between calculated properties and experimental information, such as structural conformations, spin state, and reduction potentials. Choosing which functionals to use for benchmarks is thus paramount. For instance, the B3LYP functional is a hybrid functional. In a benchmark, it is desirable to compare results against a nonhybrid functional, such as BP86 and BLYP, as performed in theoretical studies of [NiFe] hydrogenase models. ${ }^{[5 b]}$

Although DFT has been quite successfully employed in the description of energetics in main-group chemistry, this is not always the case for transition-metal compounds. Transitionmetal complexes can have access to multiple electronic configurations at near-degeneracy, which requires a multireference treatment, whereas DFT is a single-reference method. ${ }^{[19,20]} \mathrm{Nev}-$ ertheless, some functionals are shown to give reliable results in benchmarks involving transition-metal complexes, and thus, can remain as an invaluable option for theoretical calculations (see refs. [19] and [20] and references cited therein). In Section 3, we show several examples in which DFT was employed for detailed studies of redox potentials and $\mathrm{p} K_{\mathrm{a}}$ values; thus allowing for insights into the mechanisms of the HER in various transition-metal complexes.

\subsection{Reduction potential versus $\mathrm{pH}$ : Pourbaix diagrams}

Because the HER involves intertwined electrochemical and chemical steps, it can be useful to plot information regarding 
both processes, that is, reduction potentials and $\mathrm{p} K_{\mathrm{a}}$ (Scheme 2). Pourbaix diagrams are a way to visualize this relationship and provide a rich array of information about the redox-active species within the potential-pH range studied, as well as a measure of the stability of all intermediate species over a broad range of $\mathrm{pH}$ values.

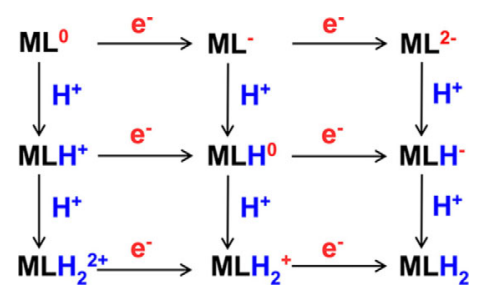

Scheme 2. Diagram representing various possible pathways and their intermediates for a metal-ligand (ML) complex.

In these diagrams, horizontal lines are plotted at the measured reduction potentials, while vertical lines are plotted for the $\mathrm{p} K_{\mathrm{a}}$ values of the catalyst. Additionally, diagonal lines separate processes involving a simultaneous oxidation and protonation process, with a slope proportional to the ratio of protons to electrons. For the reaction of $\mathrm{Ox}+n \mathrm{e}^{-}+m \mathrm{H}^{+}$ $\rightleftarrows\left[\operatorname{Red}(\mathrm{H})_{m}\right]^{m-n}$, the Nernst equation states that the reduction potential of the reaction is given by Equation (1). ${ }^{[15]}$

$$
E=-\Delta G / n F=\frac{\ln (10) R T m \log \left(\left[\mathrm{H}^{+}\right]\right)}{n F}=-0.059(m / n) \mathrm{pH}
$$

As previously mentioned, determining absolute acidity constants is problematic, but the relative $\mathrm{p} K_{\mathrm{a}}$ shifts suffice for analysis of the diagram in Figure 2. Horizontal lines separate oxidized and reduced species; the reduced one is at a lower potential. Vertical lines separate a protonation process, with a region at lower $\mathrm{pH}$ values being protonated, if compared with the one at higher $\mathrm{pH}$. Large areas in the Pourbaix diagram indicate more stable intermediates over a broad range of $\mathrm{pH}$. It is possible to establish linear correlations by using them together with redox potentials and $\mathrm{p} K_{\mathrm{a}}$ values, as seen for cobaloxime and bis-diamine nickel catalysts. ${ }^{[15,21]}$ The degree to which the

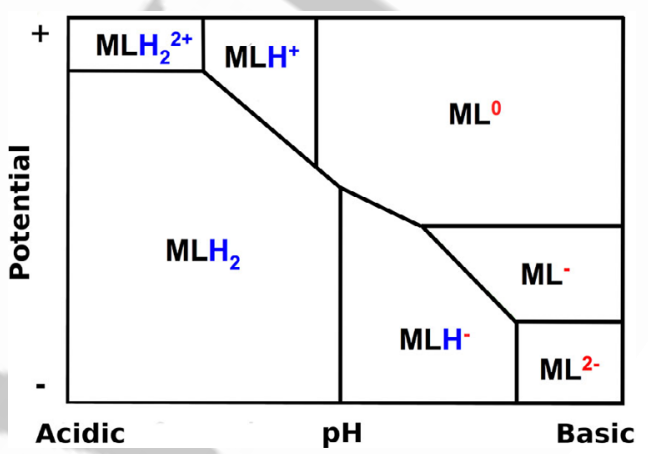

Figure 2. Representation of a hypothetical Pourbaix diagram for an organometallic catalyst with a metal center $M$ and a ligand $L$, with regions assigned to various intermediates. reduction potential becomes less negative and the $\mathrm{p} K_{\mathrm{a}}$ decreases is related to the slope of the line correlating these two properties over a range of reduction potentials and acid strengths. Such correlations are powerful tools in catalyst design, which allows computational studies to predict the properties of electrocatalysts that have not yet been synthesized.

\section{Catalytic Mechanisms of HER}

\subsection{HER in hydrogenases}

Millions of years of evolution allowed for some living systems to develop enzymes to catalyze the HER. These enzymes, known as hydrogenases, have catalytic efficiency that is unmatched by any manmade catalyst. With turnover rates of up to $10^{4} \mathrm{~s}^{-1},{ }^{[4]}$ and thanks to their thermostability and low overpotentials, hydrogenases have been seen as templates for the synthesis of new organometallic catalysts. Unfortunately, due to their intricate architecture, there has not been a precise agreement on how hydrogenases function. From the theoretical point of view, the size and composition of the active sites make them challenging subjects to study; this has become a topic of extensive discussion in the literature. Herein, we discuss some of the most recent computational studies on the mechanistic aspects of the HER in different types of hydrogenases. A more complete discussion on hydrogenases, as well as references for various experimental information, can be found in specialized reviews. ${ }^{[4,5 b]}$ For a more in-depth analysis on theoretical methods involved in these studies, we refer the reader to an excellent review by Vaissier and Van Voorhis. ${ }^{[6]}$

\subsection{1. [NiFe]-hydrogenases}

As discussed in the previous section, computational approaches have been used to elucidate the various aspects involved in catalysis of the HER, from possible protonation sites, energetics of distinct pathways, and order of electrochemical steps. There has not been a complete consensus on the catalytic cycle of [NiFe]-hydrogenases. Distinct mechanisms have been proposed by combining experimental and theoretical evidence. ${ }^{[4,22-24]}$ We present herein a few different mechanistic pathways that have been proposed over the past ten years.

Volbeda and co-workers proposed a mechanism that involved the adsorption of protons to the nickel and iron centers. ${ }^{[22]}$ Iron is found in a Fe"l low-spin state, due to interactions with the $\mathrm{CN}^{-}$and $\mathrm{CO}$ ligands (Scheme 3). ${ }^{[24]}$ Nickel would then be responsible for all redox processes in the cycle, involving two distinct oxidation states. Although the $\mathrm{Ni}^{\mathrm{III}}$ doublet state was shown to be present by using EPR techniques, ${ }^{[25]}$ there are uncertainties regarding different possible spin states for $\mathrm{Ni}^{\text {il. }{ }^{26]}}$ De Gioia and co-workers assessed this question, ${ }^{[27]}$ while investigating the energetics associated with the binding of $\mathrm{H}_{2}$ to $\mathrm{Ni}^{\prime \prime}$ at different spin states through DFT (B3LYP/TZVP). They observed that $\mathrm{H}_{2}$ binding was energetically favored for a low-spin $\mathrm{Ni}$ center and bound solely to this metal. The authors suggested a catalytic cycle in which the oxidation of $\mathrm{H}_{2}$ was followed 
a

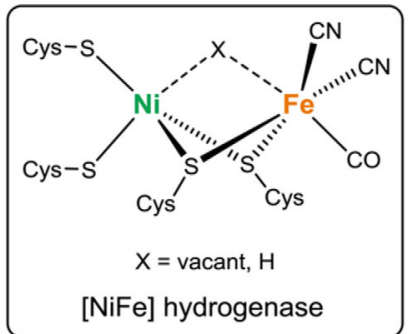

b

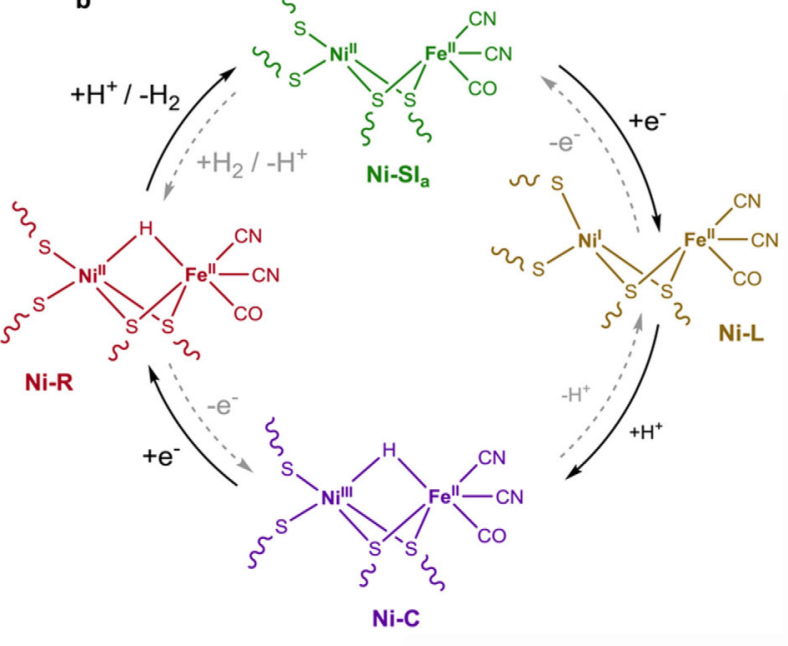

Scheme 3. a) Representation of the binuclear active site of [NiFe] hydrogenase. b) Currently accepted intermediates involved in the mechanism for the HER. ${ }^{[27-30]}$ Adapted with permission from ref. [7d]. Copyright 2016, Nature Publishing Group.

by proton transfer (PT) to one cysteine residue coordinated to $\mathrm{Ni}$. This step includes the formation of a transient $\mathrm{Ni}^{\mathrm{iV}}$ species binding the two $\mathrm{H}$ atoms. Sun and co-workers also observed a low-spin $\mathrm{Ni}^{\text {il }}$ center in their study of ligand effects. ${ }^{[28]}$ They also investigated the effect of substituting the inorganic ligands of the Fe" center, highlighting the possibility of fine-tuning the free energy landscape of the catalytic cycle. ${ }^{[4]}$

The possibility of a mechanism involving yet another redox state of nickel, Ni', was proposed by Siegbahn and Lill (B3LYP/ $D Z P){ }^{[29]}$ This reduced form would facilitate the binding and cleavage of $\mathrm{H}_{2}$ involving an oxidative addition step. Such a hypothesis was contested by De Gioia et al., whose calculations showed an energetically unfavorable process for the oxidative addition of $\mathrm{Ni}^{l}$ compared with that of $\mathrm{Ni}^{\prime \prime}$ [27] $^{27}$ They suggested PT from $\mathrm{Ni}$ to Cys546; this hypothesis was verified independently by other studies. ${ }^{[30,31]}$ Different variants of these mechanisms were investigated by Dong and Ryde, ${ }^{[30]} 31 \mathrm{a}$ ? to verify the cycle (Scheme 3) through DFT calculations (B3LYP/ def2-QZVPD) by assessing two possible pathways involving the same protonation states, but with different orders of ET and PT. In the direction of hydrogen cleavage, both mechanisms start with the unprotonated active site $\mathrm{Ni}-\mathrm{SI}_{\mathrm{a}}$ binding $\mathrm{H}_{2}$ on $\mathrm{Ni}$. The molecule is heterolytically cleaved, with $\mathrm{H}$ bound between the two metals, and the proton to Cys546, yielding the $\mathrm{Ni}-\mathrm{R}$ state. The next step involves two possibilities, in which either a proton or an electron are removed. Regardless of the order of steps, the end target intermediate is the $\mathrm{Ni}-\mathrm{C}$ state, now with $\mathrm{Ni}^{\text {III. }}$. Subsequently, the formed hydride is oxidized by $\mathrm{Ni}$, with the metal reaching its $\mathrm{Ni}^{\mathrm{l}}$ state, and the resulting proton being transferred to Cys546. At this stage, the same kind of bifurcation in the catalytic cycle as that described previously occurs. Again, the final state after bifurcation is the same, resulting in the $\mathrm{Ni}-\mathrm{Sl}_{\mathrm{a}}$ state; thus completing the cycle.

\subsection{2. [FeFe]-hydrogenases}

This type of hydrogenase shares some features with those discussed above. The catalytic center of [FeFe]-hydrogenase is composed of a proximal $\mathrm{Fe}$, bound to a [4 $\mathrm{Fe} 4 \mathrm{~S}]$ cluster, and a distal Fe, further away from the cluster. As in [NiFe]-hydrogenase, two $\mathrm{CO}$ and $\mathrm{CN}$ ligands are bound to each $\mathrm{Fe}$, with one $\mathrm{CO}$ shared between both metals. These ligands lead to Fe"l metal centers in the low-spin state. ${ }^{[4]}$ One key difference is the presence of a dithiomethylamine ligand bridging the two iron atoms. We discuss some of the parallels that exist between the catalytic cycles of [NiFe]- and [FeFe]-hydrogenases.

Similarly, with [NiFe]-hydrogenases, distinct mechanisms proposed in the literature differ mainly in the protonation sites and $\mathrm{H}_{2}$ binding. DFT calculations by the groups of Hall (B3LYP/ DZP) ${ }^{[32]}$ and Hu (PW91/plane-wave basis set) ${ }^{[33]}$ considered the distal $\mathrm{Fe}$ as the binding site and cleavage center of $\mathrm{H}_{2}$. They studied model systems that were initially inactive, in which the $\mathrm{OH}^{-}$ligand was bound to the distal iron of the Fe"Fe" unit. Reduction of the metal center to a $\mathrm{Fe}^{\prime} \mathrm{Fe}^{\prime \prime}$ state and protonation of the hydroxide results in $\mathrm{H}_{2} \mathrm{O}$ departure, leading to an active form of the metal center. An incoming hydrogen molecule binds to the distal $\mathrm{Fe}$, and the metal center is reduced to the Fe"Fe" form. The cleavage of $\mathrm{H}_{2}$ requires a proton acceptor. Both studies showed that PT from $\mathrm{H}_{2}$ to the amine group of dithiomethylamine was found to be kinetically and thermodynamically favorable. A second PT needs to take place, this time from the metal hydride formed after the first PT. Although the study by the group of Hall showed this process to be thermodynamically and kinetically possible, the pathway reported by the group of Hu suggested that a transition from a $\mathrm{H}-\mathrm{Fe}^{\prime \prime} \mathrm{Fe}$ species to $\mathrm{Fe}^{\prime} \mathrm{Fe}^{\prime}$ was unfavorable, with barriers and endothermicity of over $15 \mathrm{kcal} \mathrm{mol}^{-1}$. Instead, $\mathrm{Hu}$ and co-workers suggested that another amine group, from a lysine residue nearby, acted as the proton acceptor for this step. In this case, they found a much more favorable energy landscape. The final step in both pathways would involve an ET to bring the metal center back to a mixed-valent Fe'Fe"l state.

Independent studies by the groups of De Gioia and Zhou considered an alternative for the binding and cleavage of $\mathrm{H}_{2}$, involving a simultaneous bond to both Fe atoms. ${ }^{[34]}$ De Gioia and co-workers used DFT (B3LYP/DZP) to study a model system that was initially in the same inactive state as that in the works by the groups of $\mathrm{Hall}^{[30,31]}$ and $\mathrm{Hu}^{[32,33]}$ but achieved an active state through the same mechanism. They suggested that the active site rearranged itself to create an open site for $\mathrm{H}_{2}$ to bind. Such rearrangement in the model system, mostly involving the $\mathrm{CO}$ ligands, was shown to be slightly exothermic. The binding of $\mathrm{H}_{2}$ occurs at the proximal $\mathrm{Fe}$, with one $\mathrm{H}$ atom 
in close proximity to both iron centers. This interaction was shown to be energetically favorable. Cleavage occurs with oxidation of the iron center, leading to a Fe"Fe" state, followed by PT to an S atom of the dithiomethylamine. The protons are then transferred to the protein matrix and the FeFe unit undergoes one last oxidation, which closes the catalytic cycle and brings it back to an active form.

Apart from the difference in dihydrogen binding modes, the binding site of the $\mathrm{H}$ atom after the first PT differs. Cramer et al. used nuclear resonance vibrational spectroscopy together with DFT (BP86/LACV3P**), and determined that a metal hydride species was indeed formed, but associated only with the distal Fe atom. ${ }^{[35]}$ The reaction step associated with $\mathrm{H}_{2}$ bond formation would occur upon formation of the distal Fe-hydride complex in an optimal geometry with a second proton bound to the $\mathrm{N}$ atom of dithiomethylamine ${ }^{\left[{ }^{[3]}\right]}$ this mechanism was previously suggested by Hammes-Schiffer and co-workers for a phosphine-based [FeFe]-hydrogenase model (B3P86/ mixed basis set). ${ }^{[37]}$

\subsection{Reactivities in molecular electrocatalysts}

Although there is no consensus regarding an understanding of the complete catalytic cycle of hydrogenases, it already gives us an idea about what a proficient catalyst for HER should do. Clearly, smaller manmade catalysts lack the complex protein matrix that renders hydrogenase such a high performer. Nevertheless, general ideas behind their reactivities can be employed in the design of new molecular electrocatalysts. An excellent review by Artero and co-workers shows numerous examples of biomimetic complexes synthesized with the purpose of understanding and mimicking the proficiency of hydrogenases. $^{[9 g]}$

Currently, the best homogeneous catalysts are composed of first-row transition-metal ions, such as cobalt ${ }^{[96,38]}$ and nickel $^{[38-40]}$ (see Figure 1 for two examples). Transition metals on their own can be catalysts, mostly due to their ability to change oxidation state, and adsorb substrates onto their surfaces. However, the presence of certain ligands can have a dramatic effect. Their redox properties, as well as their capabilities of adsorbing protons, result in a variety of mechanisms for the HER. These can be classified as metal- or ligand-centered reactivity. Moreover, mechanisms differ not only in reaction centers, but also in the order in which reaction steps occur. These involve electrochemical steps (E), in which ET takes place, and chemical steps $(C)$, which involve reactions with protons. They can be stepwise, involving intermediates, or concerted, if the PTs and ETs are coupled (Scheme 4).

Other important factors to be considered are the source of protons, presence of ions, and the solvent itself; the last of which can also be an acid for proton donation. In the presence of anions, anation can take place in the complex during the PT process. Thus, accounting for these effects and possible mechanistic roles of the solvent are essential.

To understand this variety of mechanisms, one must analyze the energetics of every possible intermediate throughout the catalytic cycle. This analysis will offer valuable insight into the
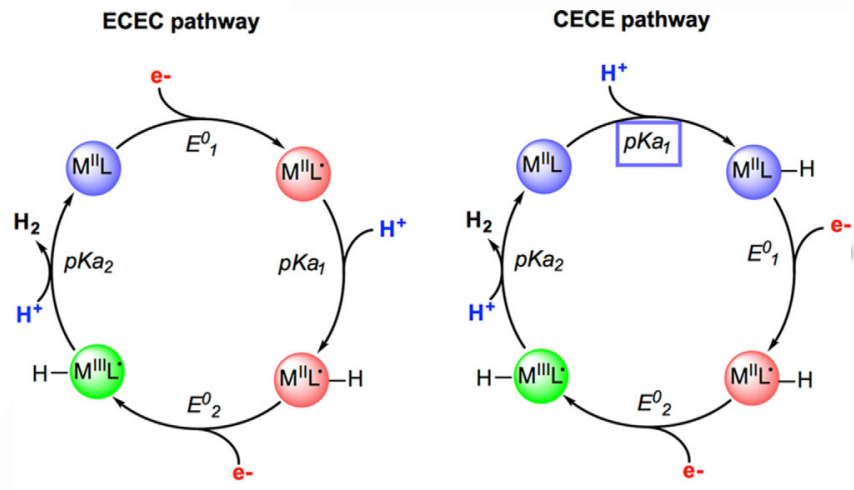

Initial state $\bigcirc \bigcirc$ Reduced intermediates $\bigcirc$ Hydride intermediates

Scheme 4. Representation of sequences and putative intermediates considered for studying the HER.

order of the steps, location of protonation sites in the catalyst, and whether one can expect stepwise or concerted processes. To illustrate this, we show examples of recent mechanistic studies of homogeneous catalysts. We examine cases involving the two possible reactive center setups, with studies showing various possibilities regarding the order of reaction steps.

\subsubsection{Metal-centered reactivity}

In this type of mechanism, the formation of $\mathrm{H}_{2}$ occurs at the metal center. The generated metal hydride will catalyze the formation of a hydrogen molecule, with the ligand assisting by binding one proton. Based on some studies discussed above, hydrogenases follow this kind of reactivity. ${ }^{[27-30]}$ This idea still inspires the development of organometallic complexes in an attempt to reproduce catalysis observed in these biological systems. For example, Duboc and co-workers sought to create a biomimetic [NiFe]-hydrogenase model ( $\mathrm{LNi}^{\prime \prime} \mathrm{Fe}^{\prime \prime} \mathrm{Cp}^{-}(\mathrm{CO}) ; \mathrm{L}=$ 2,2'-(2,2'-bipyridine-6,6'-diyl)bis(1,1-diphenylethanethiolate), $\mathrm{Cp}=$ cyclopentadienyl). ${ }^{[\mathrm{d}]}$ DFT calculations (BP86 and B3LYP/ def2-TZVP) were used to inspect specific intermediates that would be similar to those present in the catalytic cycle of [NiFe]-hydrogenase. They showed that properties calculated for these intermediates matched that of experimental infrared, EPR, and NMR spectroscopy data. Analysis of the electronic structure showed the formation of a radical in the ligand, and spin density was mostly localized at the $\mathrm{Ni}$ center upon the 
second reduction. This suggests $\mathrm{Ni}$-centered reactivity. ${ }^{[4]}$ On the other hand, Tang and Hall tested different mechanistic hypotheses (B3P86/def2-TZVP) and showed that a Fe-centered reactivity would have a lower energy pathway. ${ }^{[47]} 52$ ? The choice of their methodology was justified based on results consistent with EPR and NMR spectroscopy measurements for the initial structure, as well as a comparison of DFT-optimized and X-ray crystallographic structures. ${ }^{[7 d, 47]}$ A complete picture of the free energy profile for distinct pathways shows an Fecentered catalytic mechanism, in which protonation takes place at the Fe center and a thiol group, in an E[ECEC] mechanistic order.

Complexes mimicking [NiFe]-hydrogenases were not restrained to have a [NiFe] metal center. Prior to the NiFe complex described above, NiRu catalysts were synthesized, in an attempt to find complexes that followed similar intermediates to those detected in hydrogenases. ${ }^{[38]}$ Field et al. investigated the catalytic cycle of $\left[\mathrm{Ni}(\mathrm{L}) \mathrm{Ru}(\mathrm{CO})_{2} \mathrm{Cl}_{2}\right](\mathrm{L}=1,2$-bis(4-mercapto3,3-dimethyl-2-thiabutyl)benzene) by using DFT (BP86 and B3LYP/LACV3P** ++$)^{[39]}$ Their results showed a cycle that involved an E[CECE] pathway, through which the complex was initially activated through a two-electron reduction led by the release of $\mathrm{Cl}^{-}$, which activated the complex, $\left\{\mathrm{Ni}^{\prime} \mathrm{Ru}^{\prime}\right\}$, and generated an intermediate analogous to the $\mathrm{Ni}-\mathrm{L}$ state with a reduced center. This was followed by the formation of a hydride between both metal centers ( $\left.\mathrm{Ni}^{\prime \prime} \mathrm{Ru}^{\prime \prime}\right)$, analogous to the $\mathrm{Ni}-\mathrm{R}$ state (Scheme 3). The formation of $\mathrm{H}_{2}$ was then followed by reduction of the $\mathrm{Ni}$ center, which was then responsible for the reduction of hydrogen.

Another example of the NiRu complex, proposed by Stein and co-workers, ${ }^{[40]}$ aimed to model the $\mathrm{Ni}-\mathrm{L}$ state. They sought to synthesize a model that would reach the $\mathrm{Ni}^{\prime} \mathrm{Ru}^{\prime \prime}$ oxidation state for the bimetallic center; thus ensuring that Ni would localize the spin density for the reduction of hydrogen. Calculations performed at the B3LYP/def2-TZVP level reproduced the experimental EPR parameters and were indicative of a $\mathrm{Ni}^{\mathrm{l}}$ species. Analysis of the singly occupied molecular orbital then showed that electronic density was localized at the $\mathrm{Ni}$ center.

Bioinspired catalysts are not restricted to dinuclear complexes. Cobalt ${ }^{[42]}$ and nickel ${ }^{[43]}$ catalysts have long been seen as proficient mononuclear catalysts, ${ }^{[41]}$ and there has been continuous research into the development of novel ligands for these complexes. Ligands such as thiosemicarbazone-based ones can be redox active, as shown in a $\mathrm{Zn}$-based complex, ${ }^{[4]}$ but this is dependent on the metal center to which they are attached.

A recent study on a bis-thiosemicarbazone $\mathrm{Ni}^{\prime \prime}$ complex used DFT (B3LYP/TZVP) to study distinct mechanistic aspects of the catalytic cycle. ${ }^{[43]}$ The study assumed that the initial step of the cycle was the reduction of the complex, which was a reasonable assumption to facilitate protonation. Five distinct protonation sites were considered on $\mathrm{NiL}^{-}$: the $\mathrm{Ni}$ center; the $\mathrm{S}$ atoms; and three possible $\mathrm{N}$ atoms, those adjacent to the $\mathrm{Ni}$ center, the $\mathrm{N}$ atoms from the hydrazone group further from the metal, and the $\mathrm{N}$ atom from the phenylthiocarbamide fragment. Calculations showed a clear energetic difference between the five possible protonation states; the $\mathrm{N}$ atom bound to $\mathrm{Ni}$ was the most energetically favorable protonation site.
The proposed mechanism would be followed by a second reduction. The presence of a positive spin population at the $\mathrm{Ni}$ center suggests that the metal will become a preferential protonation site and the active species for the formation of $\mathrm{H}_{2}$. Such a cycle was proposed to be a stepwise process following an ECEC sequence. ${ }^{[45]}$ Another study, in which Ni was substituted for Co, showed the same type of mechanism; thus indicating that metal substitution would have no impact on the steps of the catalytic cycle (Scheme 5), thus retaining metal-centered reactivity. ${ }^{[42 a]}$

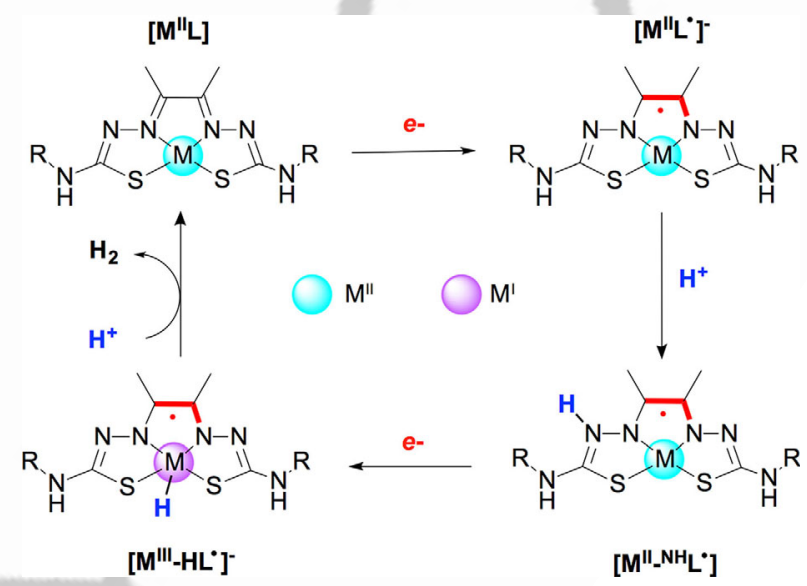

Scheme 5. Proposed mechanism for hydrogen evolution with thiosemicarbazone nickel and cobalt catalysts.

Another example of a $\mathrm{Ni}$ complex with a distinct ligand, but with a similar ECEC-type mechanism, is a $\mathrm{Ni}-\left[\mathrm{S}_{2} \mathrm{P}_{2}\right]$ complex, [Ni(bdt)(dppe)] (bdt =1,2-benzenedithiolate, dppe =1,1-bis(diphenylphosphino)ethane). ${ }^{[46]}$ In this case, the process is described in terms of two subsequent PCET steps, in which reduction precedes protonation. Another difference comes from the order of protonation, which first occurs at the Ni center and then at the $S$ atoms. An interesting mechanistic aspect of this study is that, after the adsorption of the second proton by the ligand, an intramolecular PT takes place to the Ni center; thus forming an unstable intermediate that will lead to $\mathrm{H}_{2}$ formation.

The species above involve cases in which direct metal hydride formation takes place. This is a property that will depend on the metal involved. Siegbahn and co-workers analyzed a pyridinium-based copper catalyst. ${ }^{[47]}$ Their calculations (B3LYP*D3/SDD-6-311 + G(2df,2p)) showed that direct metal hydride formation was thermodynamically unfavorable, and protonation had to occur initially at the ligand prior to formation of the $\mathrm{Cu}-\mathrm{H}$ species, followed by metal-centered reduction. The authors noted that this might not have been the case should the metal center have been either Fe or Co, for which direct metal hydride formation would have been possible. ${ }^{[47]}$

\subsubsection{Ligand-centered reactivity}

The metal center is not necessarily the center of reactivity in molecular electrocatalysts. A redox-active ligand, such as thio- 
semicarbazone, could play this role. This would allow us to relax the requirement of having a metal complex with open coordination, which should also have access to multiple redox states. We described above two cases in which bis-thiosemicarbazone was used as a ligand to assist in metal-centered reactivity. Grapperhaus $\square$ not author of ref. 47, please check $\square$ and co-workers studied two catalytic complexes with this type of ligand for the HER that did not use metal hydride intermediates: one including $\mathrm{Zn}$ and another that was metal-free. ${ }^{[47]}$ The absence of a role for the metal is mainly supported by the activity of the ligand alone. Similar calculations to assess possible protonation sites show that the hydrazino $\mathrm{N}$ atoms are the most likely proton acceptors. Nevertheless, unlike the Ni complex with bis-thiosemicarbazone previously discussed, ${ }^{[21 c]}$ DFT calculations (B97-D/6-311G(d)) did not show spin density on Zn for the various steps in the HER. Spin density indicates a radical character delocalized on the potential protonated sites of the ligand; thus reinforcing the idea of ligand-centered reactivity.

Two interesting examples of $\mathrm{Ni}$ metalloporphyrin complexes with open coordination were suggested to follow the same kind of reactivity in the presence of weak and strong acids. ${ }^{[17]}$ Hammes-Schiffer and co-workers used DFT (B3P86/mixed double- $\zeta$ ) to show different pathways, depending on the acid used. ${ }^{[17]}$ For a weak acid, an E[EECC] mechanism was suggested, starting with the reduction of the nickel center, followed by the porphyrin ring. Then PCET would occur, which could either be concerted or a sequential ET-PT mechanism. This step would involve ET between $\mathrm{Ni}$ and the ligand, followed by PT to the porphyrin, which would come either from the acid or the ligand itself, depending on the nature of the ligand. ${ }^{[17]}$ In the case of a strong acid, the order of the steps changes in the beginning, following an $E[E C E C]$ pathway. It starts with $\mathrm{Ni}$ reduction, followed by PCET, with the electron going from the $\mathrm{Ni}$ center to the porphyrin ring and protonation of the ligand.

There are several examples of catalysts in which the ligand alone does all the work, and we refer the interested reader to a specialized review by Zhang and co-workers. ${ }^{[49]}$ It is worth mentioning that it is possible for the metal to assist in the catalytic cycle, acting as a redox site, but the protonation sites are

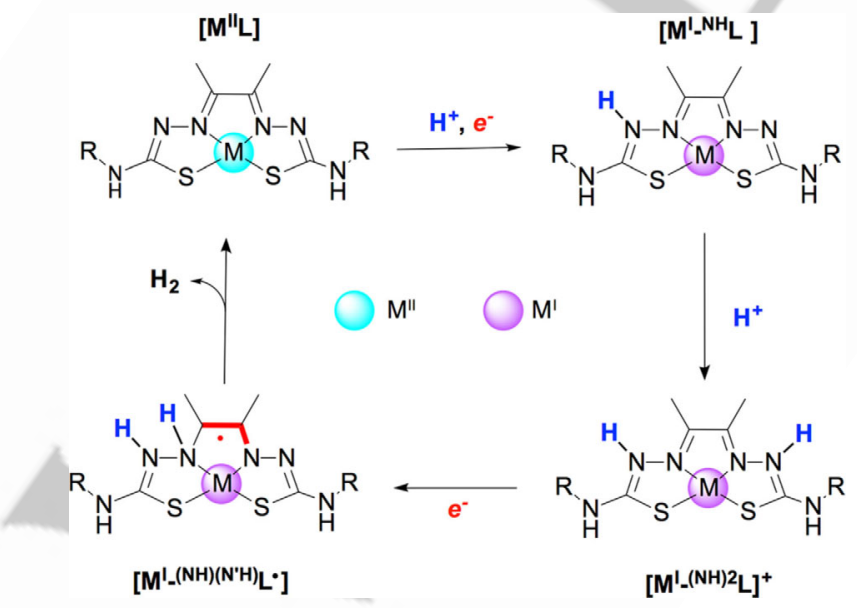

Scheme 6. Proposed mechanism for hydrogen evolution with a thiosemicarbazone copper catalyst. away from it, which requires intramolecular ET across the ligand. We discussed above a few examples involving bis-thiosemicarbazone. Grapperhaus and co-workers performed a study on a Cull complex with such a ligand. ${ }^{[50]}$ Their study involved the use of DFT (B3LYP/6-311g(d,p)) calculations to investigate the energetics associated with the stability of various intermediates for distinct spin states and protonation sites. This helped the authors to propose a CECE-type mechanism. It starts with protonation of the hydrazino $\mathrm{N}$ atom. Next, reduction of the $\mathrm{Cu}$ center takes place, followed by protonation of the second hydrazone $\mathrm{N}$ atom on the opposite side of the complex. The second reduction leads to intramolecular PT from one of the hydrazino $\mathrm{N}$ atoms to the coordinated $\mathrm{N}$ atom to the metal center adjacent to the opposing protonated hydrazino $\mathrm{N}$ atom. The metal center acts as an electron donor for $\mathrm{H}_{2}$ formation taking place in the ligand (Scheme 6). ${ }^{[50]}$

\subsection{Environmental effects}

The environment plays an important role in modulating the energetics of every intermediate state in a chemical reaction, as well as being a source of protons, coming from solvent molecules or acids present in solution. The polarity of the solvent dictates the dielectric constant, which affects the screening of Coulombic interactions for PT and ET. This would impact on the energies of every intermediate, and consequently, on the redox potentials and $\mathrm{p} K_{\mathrm{a}}$ values. It can also affect the geometry of the complex, in which the presence of hydrogen bonds can stabilize distinct conformations to those more prevalent in nonpolar solvents. ${ }^{[29]}$ Additionally, solvent molecules can bind to the complex, modulating its molecular orbitals to facilitate reduction. This role can also be played by ions in the solution in a process known as anation. All of these possibilities must be considered when looking at mechanistic alternatives (Scheme 7).

The proton source can have an impact on the electrocatalytic potential of the complex. Anodic shifts of more than $300 \mathrm{mV}$ were observed for $\mathrm{Co}$ and $\mathrm{Ni}$ diimine-dioxime complexes in the presence of strong acids used as proton sources. The shifts are observed for specific oxidation states of the complex, as well as at particular protonation states, and thus, are a useful piece of information for studying possible catalytic mechanisms. Solis et al. described this anodic shift effect theoretically in a series of cobalt-oxime complexes by using DFT (B3P86/6$311+G(d, p))$ due to protonation on the oxime bridge, ${ }^{[54]}$ and calculated $\mathrm{p} K_{\mathrm{a}}$ values for the possible oxidation states of the metal center; thus offering insights into the strength of the acid required for protonation. This information is then used to inspect the feasibility of different pathways for their catalytic cycle. Artero and co-workers arrived at similar conclusions upon directly calculating the redox potentials for a cobalt diimine-dioxime catalyst in the presence of different acids. ${ }^{[55]}$

An example of such an investigation was performed by Panneerselvam and Jaccob, ${ }^{[56]}$ based on experimental studies by Chang and co-workers. ${ }^{[57]}$ They used DFT (B3LYP/6-31G(d)) calculations to study proton reduction involving a Co" center with a pentapyridyl ligand solvated by acetonitrile in the pres- 


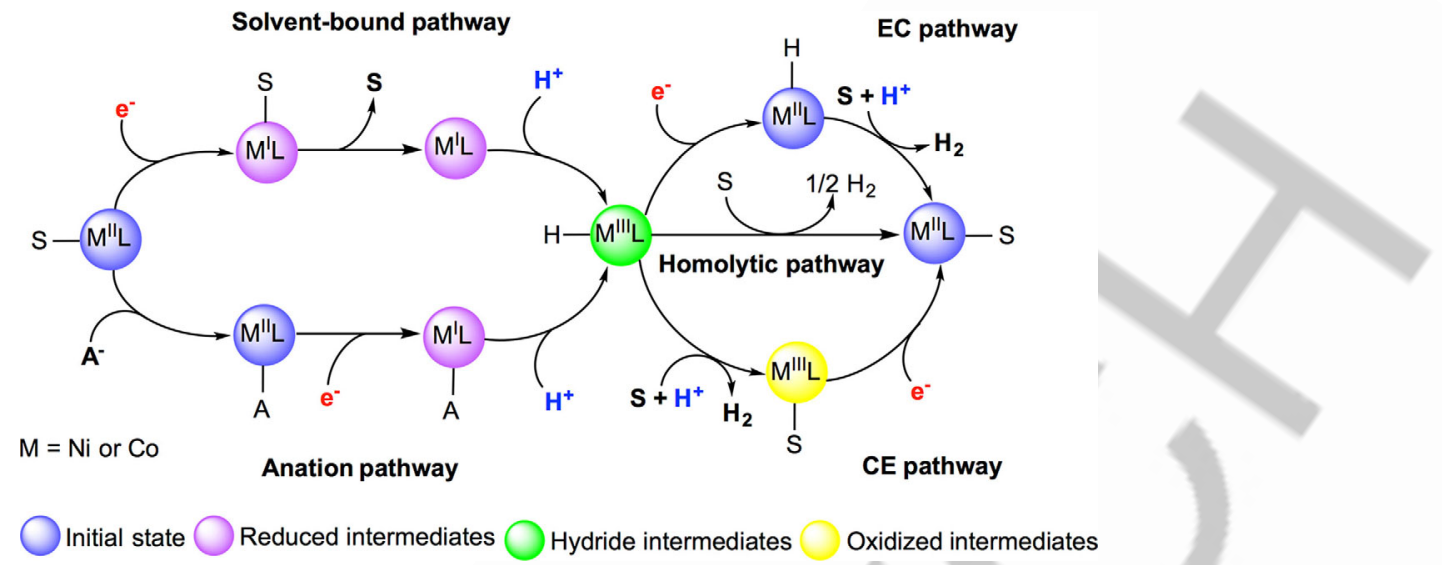

Scheme 7. Representation of the solvent-bound and anation reaction pathways to form hydride intermediates.

ence of acetate anions. They investigated various different mechanistic pathways, such as cooperative reduction between singly protonated complexes, unimolecular homolytic cleavage, and pathways involving anation at distinct intermediate steps. They wanted to assess the role of acetate ions in the reduction of the complex to a $\mathrm{Co}^{\mathrm{III}}-\mathrm{H}$ species. Whereas the protonation of $\mathrm{Co}^{\prime}$ was shown to be the rate-limiting step, anation of the complex, substituting a bound acetonitrile with an acetate ion, was shown to alter the energetics of proton reduction. They showed that the substitution step was rate determining in the anation pathway. Subsequently, reduction is followed by rapid PT, leading to $\mathrm{CO}^{\mathrm{III}}-\mathrm{H}$ formation. A comparison between the various pathways studied therein shows the importance of anation for this complex.

As with anation, the solvent-bound complex will have different properties, such as modulation of the redox potential of the complex. An example by Hammes-Schiffer and co-workers used DFT (B3P86/mixed basis set) to show a plausible mechanism to describe catalysis of the HER for a [Ni(PPhN)] complex in acetonitrile, in which the solvent plays such role. ${ }^{[58]}$ In this particular case, the binding of $\mathrm{CH}_{3} \mathrm{CN}$ changes the geometry of the $\mathrm{Ni}$ center, from a tetrahedral coordination to a pentacoordinate center, with the addition of an extra electron from the ligand itself to the metal center. The ligand can then affect the stability of the various oxidation states of Ni. In this case, accurate estimates of redox potentials need to take into account the possibility of ligand release. ${ }^{[58]}$ Additionally, the authors generated a theoretical Pourbaix diagram to illustrate the distinct possible PCET process that could take place in the catalytic cycle, such as one-electron/one-proton and two-electron/ one-proton processes, and the two-electron/two-proton process observed experimentally for a range of $\mathrm{pH}$ values between 7 and 12.

All information obtained from these effects can be used in the optimization of catalysts. One way is by manipulating relative $\mathrm{p} K_{\mathrm{a}}$ values of the complex through substituents ${ }^{[21 \mathrm{a}]}$ or by choosing different acids and/or solvents. Theoretical Pourbaix diagrams are essential for such a purpose, ${ }^{[15,58]}$ thus allowing tests on how changes in acidity and reduction potentials can lead to a more spontaneous catalytic cycle.

\section{Summary and Outlook}

Nowadays most research groups usually combine experiment and theory to investigate molecular entities related to biological systems. Quantum chemistry has been established as a valuable tool that can serve either to validate the conclusions that have been drawn from experimental data or to distinguish between those possibilities that are left open. Theoretical calculations thus allow a close connection with experiment and often lead to important clues about the electronic and spectroscopic properties, as well as the reactivity, of the systems under studied.

Herein, we have discussed the current theoretical approaches used to decipher reactions mechanisms involving small-molecule catalysts for the electrochemical HER. We have presented many possible types of catalytic cycles and our current understanding in the context of the most recent bioinspired and biomimetic homogeneous HER catalysts. We have shown that computations can be used to model reduction potentials and $\mathrm{p} K_{\mathrm{a}}$ values to investigate the thermodynamics and mechanisms of the HER. They are useful to generate free energy reaction pathways and Pourbaix diagrams, to eventually identify the thermodynamically favorable mechanisms and to indicate the most stable species under specified experimental conditions.

Theoretical calculations are also important to predict the effects of different substituents, ligands, and metal centers on the electronics, thermodynamics, and mechanisms of molecular electrocatalysts. The correlation between theory and experiment is critical to test and validate the theoretical predictions, and drive the methodological developments toward experimentally accessible systems. The value of theoretical calculations is thus not limited to rationalizing experimental observations. In conjunction with experimental validation, numerical approaches can play a key role in the efforts to design efficient catalysts, and to assist in the development of new homogeneous catalysts. Numerical investigations reported in the literature thus provide a proof-of-concept that quantum chemistry can be used nowadays as a predictive tool to rationalize reac- 
tivity, enhance catalytic activity, and guide the design of new synthetic targets for the HER.

Important directions to be followed for the future design of HER catalysts were recently discussed by Zhang and co-workers. ${ }^{[49]}$ Most current research is actually focused on developing electrocatalysts that feature metal-centered reactivity. Nevertheless, it seems that redox-active catalysts promoting electroand photochemical ligand-centered hydrogen evolution, as well as metal-free organic compounds, are very promising leads to interesting discoveries and creative ideas in the design of innovative molecular catalysts.

Ultimately, the development of hydrogen evolution catalysts will contribute to a better understanding of the catalytic mechanism of $\mathrm{H}_{2}$ formation by hydrogenases and to the development of efficient mimics that model not only the structure and function of the active site of this enzyme, but also its impressive reactivity.

\section{Acknowledgements}

We gratefully acknowledge research support of this work by the Agence National de la Recherche (grant no. ANR-16-CE92-001201) and the Deutsche Forschungsgemeinschaft (grants no. DFG Me1313/14-1, NiFeMim).

\section{Conflict of interest}

The authors declare no conflict of interest.

Keywords: electrochemistry · enzyme models · hydrogenases · quantum chemistry $\cdot$ reaction mechanisms

[1] D. A. King, Science 2004, 303, 176-177.

[2] a) J. A. Turner, Science 2004, 305, 972-974; b) P. P. Edwards, V. L. Kuznetsov, W. I. F. David, N. P. Brandon, Energy Policy 2008, 36, 4356-4362.

[3] A. Fujishima, K. Honda, Nature 1972, 238, 37-38.

[4] W. Lubitz, H. Ogata, O. Rdiger, E. Reijerse, Chem. Rev. 2014, 114, 4081 4148.

[5] a) J. C. Fontecilla-Camps, A. Volbeda, C. Cavazza, Y. Nicolet, Chem. Rev. 2007, 107, 4273-4303; b) P. E. M. Siegbahn, J. W. Tye, M. B. Hall, Chem. Rev. 2007, 107, 4414-4435; c) D. Schilter, J. M. Camara, M. T. Huynh, S Hammes-Schiffer, T. B. Rauchfuss, Chem. Rev. 2016, 116, 8693-8749.

[6] V. Vaissier, T. Van Voorhis, Essays Biochem. 2017, 61, 293-303.

[7] a) T. B. Rauchfuss, Acc. Chem. Res. 2015, 48, 2107-2116; b) M. Y. Darensbourg, E. J. Lyon, J. J. Smee, Coord. Chem. Rev. 2000, 206, 533-561; c) Z. Li, Y. Ohki, K. Tatsumi, J. Am. Chem. Soc. 2005, 127, 8950-8951; d) D. Brazzolotto, M. Gennari, N. Queyriaux, T. R. Simmons, J. Pécault, S. Demeshko, F. Meyer, M. Orio, V. Artero, C. Duboc, Nat. Chem. 2016, 8, 1054-1060; e) S. Canaguier, M. Field, Y. Oudart, J. Pécaut, M. Fontecave, V. Artero, Chem. Commun. 2010, 46, 5876-5878; f) K. Weber, T. Krämer, H. S. Shafaat, T. Weyhermüller, E. Bill, M. van Gastel, F. Neese, W. Lubitz, J. Am. Chem. Soc. 2011, 141, 472-481ロJ. Am. Chem. Soc. 2012, 134, 20745-20755? ref not found, please check $\mathbf{\square}$.

[8] a) M. L. Helm, M. P. Stewart, R. M. Bullock, M. R. DuBois, D. L. DuBois, Science 2011, 333, 863-866; b) M. Ravazet, V. Artero, M. Fontecave, Inorg. Chem. 2005, 44, 4786-4795; c) P. Zhang, M. Wang, Y. Yang, T. Yao, L. Sun, Angew. Chem. Int. Ed. 2014, 53, 13803-13807; Angew. Chem. 2014, 126, $14023-14027$; d) S. Cherdo, S. El Ghachtouli, M. Sircoglou, F. Brisset, M. Orio, A. Aukauloo, Chem. Commun. 2014, 50, 13514-13516; e) E. J. Thompson, L. A. Berben, Angew. Chem. Int. Ed. 2015, 54, 11642 11646; Angew. Chem. 2015, 127, 11808-11812; f) M. Beyler, S. Ezzaher,
M. Karnahl, M.-P. Santoni, R. Lomoth, S. Ott, Chem. Commun. 2011, 47, $11662-11664$; g) H. I. Karunadasa, C. J. Chang, J. R. Long, Nature 2010, 464, 1329- 1333 .

[9] a) V. Artero, M. Fontecave, Coord. Chem. Rev. 2005, 249, 1518-1535; b) F. Gloaguen, T. B. Rauchfuss, Chem. Soc. Rev. 2009, 38, 100-108; c) S. Fukuzumi, Y. Yamada, T. Suenobu, K. Ohkubo, H. Kotani, Energy Environ Sci. 2011, 4, 2754-2766; d) P. Du, R. Eisenberg, Energy Environ. Sci. 2012, 5, 6012-6021; e) J. R. McKone, S. C. Marinescu, B. S. Brunschwig, J. R. Winkler, H. B. Gray, Chem. Sci. 2014, 5, 865-878; f) T. R. Simmons, V. Artero, Angew. Chem. Int. Ed. 2013, 52, 6143-6145; Angew. Chem. 2013, $125,6259-6261$; g) T. R. Simmons, G. Berggren, M. Bacchi, M. Fontecave, V. Artero, Coord. Chem. Rev. 2014, 270-271, 127-150.

[10] S. Hammes-Schiffer, Acc. Chem. Res. 2018, 51, 1975-1983.

[11] W. L. Jorgensen, L. L. Thomas, J. Chem. Theory Comput. 2008, 4, 869876.

[12] M. W. Schmidt, K. K. Baldridge, J. A. Boatz, S. T. Elbert, M. S. Gordon, J. H. Jensen, S. Koseki, N. Matsunaga, K. A. Nguyen, S. J. Su, T. L. Windus, M. Dupuis, J. A. Montgomery, J. Comput. Chem. 1993, 14, 1347-1363.

[13] F. Neese, WIREs Comput. Mol. Sci. 2012, 2, 73-78.

[14] C. J. Cramer, D. G. Truhlar, Chem. Rev. 1999, 99, 2161-2200.

[15] a) B. H. Solis, S. Hammes-Schiffer, Inorg. Chem. 2014, 53, 6427-6443; b) L. Yan, Y. Lub, X. Lia, Phys. Chem. Chem. Phys. 2016, 18, 5529-5536; c) M.-H. Baik, R. A. Friesner, J. Phys. Chem. A 2002, 106, 7407-7412.

[16] G. C. Shields, P. G. Seybold in Computational Approaches for the Prediction of $p K_{a}$ Values, 1st ed., CRC Press, Boca Raton, FL, 2013.

[17] B. H. Solis, A. G. Maher, D. K. Dogutan, D. G. Nocera, S. Hammes-Schiffer, Proc. Natl. Acad. Sci. USA 2016, 113, 485-492.

[18] a) A. Bhattacharjee, E. S. Andreiadis, M. Chavarot-Kerlidou, M. Fontecave, M. J. Field, V. Artero, Chem. Eur. J. 2013, 19, 15166-15174; b) A. Zarkadoulas, M. J. Field, V. Artero, C. A. Mitsopoulou, ChemCatChem 2017, 9, 2308-2317; c) K. Ye, Y.-Y. Li, R.-Z. Liao, RSC Adv. 2016, 6, 90035-90045.

[19] a) J. N. Harvey, Annu. Rep. Prog. Chem. Sect. C 2006, 102, 203-226; b) C. J. Cramer, D. G. Truhlar, Phys. Chem. Chem. Phys. 2009, 11, 1075710816.

[20] M. Mardirossian, M. Head-Gordon, Mol. Phys. 2017, 115, 2315-2372.

[21] a) B. H. Solis, S. Hammes-Schiffer, J. Am. Chem. Soc. 2011, 133, 1903619039 ; b) Y. A. Small, D. L. DuBois, E. Fujita, J. T. Muckerman, Energy Environ. Sci. 2011, 4, 3008-3020.

[22] J. C. Fontecilla-Camps, P. Amara, C. Cavazza, Y. Nicolet, A. Volbeda, Nature 2009, 460, 814-822.

[23] T. Yagi, S. Ogo, Y. Higuchi, Int. J. Hydrogen Energy 2014, 39, 18543 18550.

[24] S. Kaur-Ghumaan, M. Stein, Dalton Trans. 2014, 43, 9392-9405.

[25] R. Cammack, D. Patil, R. Aguirre, E. C. Hatchikian, FEBS Lett. 1982, 142, 289-292.

[26] a) C. P. Wang, R. Franco, J. J. Moura, I. Moura, E. P. Day, J. Biol. Chem 1992, 267, 7378-7380; b) S. Niu, L. M. Thomson, M. B. Hall, J. Am. Chem. Soc. 1999, 121, 4000-4007; c) H. Wang, C. Y. Ralston, D. S. Patil, R. M. Jones, W. Gu, M. Verhagen, M. Adams, P. Ge, C. Riordan, C. A. Marganian, P. Mascharak, J. Kovacs, C. G. Miller, T. J. Collins, S. Brooker, P. D. Croucher, K. Wang, E.I. Stiefel, S. P. Cramer, J. Am. Chem. Soc. 2000, 122, 10544-10552; d) W. Gu, L. Jacquamet, D. S. Patil, H. Wang, D. J. Evans, M. C. Smith, M. Millar, S. Koch, D. M. Eichhorn, M. Latimer, S. P. Cramer, J. Inorg. Biochem. 2003, 93, 41-51; e) A. Pardo, A. L. De Lacey, V. M. Fernández, H. Fan, Y. Fan, M. B. Hall, J. Biol. Inorg. Chem. 2006, 11, 286306.

[27] M. Bruschi, M. Tiberti, A. Guerra, L. De Gioia, J. Am. Chem. Soc. 2014, 136, $1803-1814$.

[28] S. Qiu, L. M. Azofra, D. R. MacFarlane, C. Sun, ACS Catal. 2016, 6, 5541 5548.

[29] S. O. N. Lill, P. E. M. Siegbahn, Biochemistry 2009, 48, 1056-1066.

[30] M. Kampa, W. Lubitz, M. van Gastel, F. Neese, J. Biol. Inorg. Chem. 2012, $17,1269-1281$.

[31] a) G. Dong, U. Ryde, J. Biol. Inorg. Chem. 2016, 21, 383-394; b) G. Dong, Q. M. Phung, K. Pierloot, U. Ryde, Inorg. Chem. 2018, 57, 15289-15298.

[32] a) Z. Cao, M. B. Hall, J. Am. Chem. Soc. 2001, 123, 3734-3742; b) H. Fan, M. B. Hall, J. Am. Chem. Soc. 2001, 123, 3828-3829.

[33] a) Z. Liu, P. Hu, J. Am. Chem. Soc. 2002, 124, 5175-5182; b) Z. Liu, P. Hu, J. Chem. Phys. 2002, 117, 8177-8180.

[34] a) M. Bruschi, P. Fantucci, L. De Gioia, Inorg. Chem. 2002, 41, 1421 1429; b) M. Bruschi, P. Fantucci, L. De Gioia, Inorg. Chem. 2003, 42, 
4773-4781; c) T. Zhou, Y. Mo, Z. Zhou, K. Tsai, Inorg. Chem. 2005, 44 4941-4946; d) G. Zampella, C. Greco, P. Fantucci, L. De Gioia, Inorg. Chem. 2006, 45, 4109-4118.

[35] E. J. Reijerse, C. C. Pham, V. Pelmenschikov, R. Gilbert-Wilson, A. Adamska-Venkatesh, J. F. Siebel, L. B. Gee, Y. Yoda, K. Tamasaku, W. Lubitz, T. B. Rauchfuss, S. P. Cramer, J. Am. Chem. Soc. 2017, 139, 4306-4309.

[36] V. Pelmenschikov, J.A. Birrell, C. C. Pham, N. Mishra, H. Wang, C. Sommer, E. Reijerse, C. P. Richers, K. Tamasaku, Y. Yoda, T. B. Rauchfuss, W. Lubitz, S. P. Cramer, J. Am. Chem. Soc. 2017, 139, 16894-16902.

[37] M. T. Huynh, W. Wang, T. B. Rauchfuss, S. Hammes-Schiffer, Inorg. Chem 2014, 53, $10301-10311$.

[38] a) S. Canaguier, V. Artero, M. Fontecave, Dalton Trans. 2008, 315-325 b) M. A. Reynolds, T. B. Rauchfuss, S. R. Wilson, Organometallics 2003, 22 $1619-1625$; c) T. B. Rauchfuss, Science 2007, 316, 553-554; d) Y. Oudart V. Artero, L. Norel, C. Train, J. Pécaut, M. Fontecave, J. Organomet. Chem. 2009, 694, 2866-2869; e) Y. Oudart, V. Artero, J. Pécaut, M. Fontecave, Inorg. Chem. 2006, 45, 4334-4336; f) Y. Oudart, V. Artero, J. Pécaut, C. Lebrun, M. Fontecave, Eur. J. Inorg. Chem. 2007, 2613-2626.

[39] L. Vaccaro, V. Artero, S. Canaguier, M. Fontecave, M. J. Field, Dalton Trans. 2010, 39, 3043-3049.

[40] G. M. Chambers, J. Mitra, T. B. Rauchfuss, M. Stein, Inorg. Chem. 2014 $53,4243-4249$

[41] a) S. Losse, J. G. Vos, S. Rau, Coord. Chem. Rev. 2010, 254, 2492-2504 b) V. Artero, M. Chavarot-Kerlidou, M. Fontecave, Angew. Chem. Int. Ed. 2011, 50, 7238-7266; Angew. Chem. 2011, 123, 7376-7405; c) N. Queyriaux, R. T. Jane, J. Massin, V. Artero, M. Chavarot-Kerlidou, Coord. Chem. Rev. 2015, 304-305, 3-19; d) J. Wang, W. Cui, Q. Liu, Z. Xing, A. M. Asiri, X. Sun, Adv. Mater. 2016, 28, 215-230.

[42] a) T. Straistari, R. Hardré, J. Fize, S. Shova, M. Giorgi, M. Réglier, V. Artero, M. Orio, Chem. Eur. J. 2018, 24, 8779-8786; b) J. L. Dempsey, B. S Brunschwig, J. R. Winkler, H. B. Gray, Acc. Chem. Res. 2009, 42, 1995 2004; c) J. L. Dempsey, J. R. Winkler, H. B. Gray, J. Am. Chem. Soc. 2010, 132, 16774-16776; d) E. S. Wiedner, A. M. Appel, D. L. DuBois, R. M. Bullock, Inorg. Chem. 2013, 52, 14391 -14403; e) E. S. Wiedner, J. A. S. Roberts, W. G. Dougherty, W. S. Kassel, D. L. DuBois, R. M. Bullock, Inorg Chem. 2013, 52, 9975-9988; f) V. Artero, J.-M. Saveant, Energy Environ. Sci. 2014, 7, 3808-3814; g) N. Kaeffer, M. Chavarot-Kerlidou, V. Artero Acc. Chem. Res. 2015, 48, 1286-1295.

[43] a) A. D. Wilson, R. H. Newell, M. J. McNevin, J.T. Muckerman, M. R. DuBois, D. L. DuBois, J. Am. Chem. Soc. 2006, 128, 358-366; b) X. Jing P. Wu, X. Liu, L. Yang, C. He, C. Duan, New J. Chem. 2015, 39, 1051 1059 ; c) T. Straistari, J. Fize, S. Shova, M. Réglier, V. Artero, M. Orio ChemCatChem 2017, 9, 2262-2268.
[44] a) S. Blanchard, E. Bill, T. Weyhermüller, K. Wieghardt, Inorg. Chem. 2004 43, 2324-2329; b) S. Blanchard, F. Neese, E. Bothe, E. Bill, T. Weyhermüller, K. Wieghardt, Inorg. Chem. 2005, 44, 3636-3656; c) M. A. Ali, P. V. Bernhardt, M. A. H. Brax, J. England, A. J. Farlow, G. R. Hanson, L. Yeng, A. H. Mirza, K. Wieghardt, Inorg. Chem. 2013, 52, 1650-1657; d) D. L. DuBois, Inorg. Chem. 2014, 53, 3935-3960; e) N. Coutard, N. Kaeffer, V. Artero, Chem. Commun. 2016, 52, 13728-13748. Dnot cited in text, please check

[45] R. Jain, A. Mamun, R. M. Buchanan, P. M. Kozlowski, C. A. Grapperhaus, Inorg. Chem. 2018, 57, 13486-13493.

[46] R. Das, F. Neese, M. van Gastel, Phys. Chem. Chem. Phys. 2016, 18, $24681-24692$.

[47] R. Liao, M. Wang, L. Sun, P. E. M. Siegbahn, Dalton Trans. 2015, 44, 9736-9739.

[48] A. Z. Haddad, B. D. Garabato, P. M. Kozlowski, R. M. Buchanan, C. A. Grapperhaus, J. Am. Chem. Soc. 2016, 138, 7844-7847.

[49] G.-G. Luo, H.-L. Zhang, Y.-W. Tao, Q.-Y. Wu, D. Tian, Q. Zhang, Inorg. Chem. Front. 2019, 6, 343-354.

[50] A. Z. Haddad, S. P. Cronin, M. S. Mashuta, R. M. Buchanan, C. A. Grapperhaus, Inorg. Chem. 2017, 56, 11254-11265.

[51] a) M. Raynal, P. Ballester, A. Vidal-Ferran, P. W. N. M. van Leeuwen, Chem Soc. Rev. 2014, 43, 1660-1733; b) P. J. Dyson, P. G. Jessop, Catal. Sci. Technol. 2016, 6, 3302-3316. $\square$ not cited in text, please check $\square$

[52] H. Tang, M. B. Hall, J. Am. Chem. Soc. 2017, 139, 18065-18070. ם not cited in text, please check

[53] a) X. Hu, B. M. Cossairt, B. S. Brunschwig, N. S. Lewis, J. C. Peters, Chem Commun. 2005, 4723-4725; b) P. A. Jacques, V. Artero, J. Pécaut, M Fontecave, Proc. Natl. Acad. Sci. USA 2009, 106, 20627-20632; c) C. C. L. McCrory, C. Uyeda, J. C. Peters, J. Am. Chem. Soc. 2012, 134, 3164-3170. 口not cited in text, please check

[54] B. H. Solis, Y. Yu, S. Hammes-Schiffer, Inorg. Chem. 2013, 52, 6994-6999.

[55] See ref. [18a]

[56] M. Panneerselvam, M. Jaccob, Inorg. Chem. 2018, 57, 8116-8127.

[57] A. E. King, Y. Surendranath, N. A. Piro, J. P. Bigi, J. R. Long, C. J. Chang, Chem. Sci. 2013, 4, 1578-1587.

[58] S. Horvath, L. E. Fernandez, A. M. Appel, S. Hammes-Schiffer, Inorg.

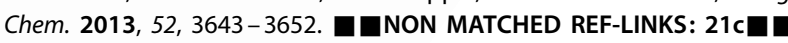

Manuscript received: July 5, 2019

Revised manuscript received: August 22, 2019

Accepted manuscript online: September 26, 2019

Version of record online: $\mathbf{m}, 0000$ 
MINIREVIEWS

A. Barrozo, ${ }^{*}$ M. Orio*

ח-

Molecular Electrocatalysts for the Hydrogen Evolution Reaction: Input from Quantum Chemistry

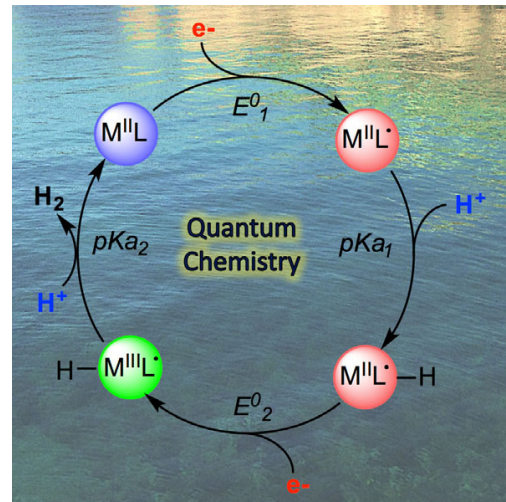

Theoretical nature: The design of molecular electrocatalysts for hydrogen production is important for the development of renewable energy sources that are abundant, inexpensive, and environmentally benign. Theoretical mechanistic studies of biomimetic and bioinspired homogeneous hydrogen evolution catalysts are reviewed.

Theoretical nature: Biomimetic and bioinspired homogeneous hydrogen evolution catalysts based on \#hydrogenases are reviewed \#electrochemistry @univamu SPACE RESERVED FOR IMAGE AND LINK

Share your work on social media! ChemSusChem has added Twitter as a means to promote your article. Twitter is an online microblogging service that enables its users to send and read short messages and media, known as tweets. Please check the pre-written tweet in the galley proofs for accuracy. If you, your team, or institution have a Twitter account, please include its handle @username. Please use hashtags only for the most important keywords, such as \#catalysis, \#nanoparticles, or \#proteindesign. The ToC picture and a link to your article will be added automatically, so the tweet text must not exceed 250 characters. This tweet will be posted on the journal's Twitter account (follow us@ChemSusChem) upon publication of your article in its final (possibly unpaginated) form. We recommend you to re-tweet it to alert more researchers about your publication, or to point it out to your institution's social media team.

Please check that the ORCID identifiers listed below are correct. We encourage all authors to provide an ORCID identifier for each coauthor. ORCID is a registry that provides researchers with a unique digital identifier. Some funding agencies recommend or even require the inclusion of ORCID IDs in all published articles, and authors should consult their funding agency guidelines for details. Registration is easy and free; for further information, see http://orcid.org/.

Dr. Alexandre Barrozo

Dr. Maylis Orio http://orcid.org/0000-0002-9317-8005 